\title{
Robot-assisted stereotactic brainstem biopsy in children: prospective cohort study
}

\author{
William Dawes $^{1} \cdot$ Hani J. Marcus ${ }^{1,2}\left(\mathbb{D}^{-} \cdot\right.$ Martin Tisdall $^{1} \cdot$ Kristian Aquilina $^{1}$
}

Received: 26 July 2018 / Accepted: 28 November 2018 / Published online: 6 December 2018

(c) The Author(s) 2018

\begin{abstract}
Tumours located within the brainstem comprise approximately a tenth of all paediatric brain tumours. Surgical biopsy of these tumours is technically challenging and has historically been associated with considerable risk. To this end, robotassisted surgery theoretically allows for increased accuracy and precision. In this study we report our experience using the Neuromate robot (Renishaw, Gloucestershire, UK) to perform robot-assisted stereotactic biopsy in children with tumours located within the brainstem. An uncontrolled prospective cohort study was performed (phase II) according to the IDEAL model for safe surgical innovation. All cases were recorded on a prospectively maintained database. The database was searched over a 2-year period between the 1st December 2015 and the 31st November 2017 to identify all children with brainstem tumours that underwent robot-assisted stereotactic brain biopsy. When accessible, the post-operative MRI scans and pre-operative plans were compared to assess the target point localisation error (TPLE). Adverse events were recorded prospectively according to whether they resulted in increased hospital stay, caused neurological injury, or lead to death. In all, 11 consecutive children were identified with brain tumours located within the brainstem. In 10/11 cases specimens were diagnostic; in the remaining case a further biopsy was successful. The most frequent pathology was DIPG (7/15). Seven patients underwent an early post-operative volumetric MRI; the calculated median TPLE was $2.7 \mathrm{~mm}$ (range 0.5-4.2 mm). There were no surgical complications noted. Robot-assisted stereotactic biopsy in children appears to be feasible and safe. Research databases and comparative studies are warranted to further assess the technique.
\end{abstract}

Keywords Surgery $\cdot$ Robotics $\cdot$ Stereotaxy $\cdot$ Diffuse intrinsic brainstem glioma $\cdot$ DIPG

\section{Introduction}

Tumours located within the brainstem comprise approximately a tenth of all paediatric brain tumours [1]. The most common of these tumours is diffuse intrinsic pontine glioma (DIPG). As DIPG is associated with a characteristic MRI appearance and can be diagnosed from imaging alone, it has been argued that brainstem biopsy is not warranted in most cases [2]. In addition, the majority of children with DIPG

William Dawes and Hani J. Marcus contributed equally.

Hani J. Marcus

h.marcus@ucl.ac.uk

1 Department of Neurosurgery, Great Ormond Street Hospital, London, UK

2 Wellcome EPSRC Centre for Interventional and Surgical Sciences, University College London, 8.02 Malet Place Building, Gower Street, London WC1E 6BT, UK die within 2 years of diagnosis, and information obtained from biopsy has, up to now, not altered treatment strategy [3]. However, recent studies have suggested that molecular markers may aid prognostication [4]. Several clinical trials that utilise these molecular markers to personalise treatment regimens are now underway. The BIOMEDE trial (NCT02233049), for example, specifically randomises treatment to targets identified on biopsy, and importantly withholds treatment to targets that are not identified. A prerequisite to the enrolment of patients into such clinical trials is the acquisition of brain tumour tissue.

Surgical biopsy of brainstem tumours is technically challenging and has historically been associated with considerable risk [2]. Stereotactic brain biopsy is generally preferred to open biopsy unless an exophytic tumour component is identified. The most common trajectories are transcortical (transfrontal) via the cerebral peduncle and transcerebellar via the middle cerebellar peduncle; the former requires a longer trajectory and carries a risk of injury to the ventricles, 
while the latter is performed prone and necessitates dissection of the nuchal musculature that is associated with increased pain. Whichever approach is selected, high accuracy and precision is mandated; if these requirements are met, a number of publications have demonstrated that the risks of brainstem tumour biopsy are potentially low [5-7].

Robot-assisted surgery theoretically allows for increased accuracy and precision. The first report of a robot-assisted stereotactic brain biopsy was in 1985 when a modified PUMA industrial robot (Advance Research and Robotics, CT, USA) was used to define the trajectory [8]. Although several subsequent studies have concluded that robotassisted stereotactic brain biopsy is feasible and safe [8-13], few have focused on children with brainstem pathology, who represent a unique patient group.

In this study, we report our experience using the Neuromate robot (Renishaw, Gloucestershire, UK) to perform robot-assisted stereotactic biopsy in children with tumours located within the brainstem.

\section{Methods}

The study was registered as a Service Evaluation study with the Great Ormond Street Hospital for Children NHS Foundation Trust Clinical Audit Committee (\#2237). Informed consent was not sought, as this was a Service Evaluation study.

An uncontrolled prospective cohort study was performed (phase II) according to the IDEAL model for safe surgical innovation. The Strengthening the Reporting of Observational Studies in Epidemiology (STROBE) Statement was used in the preparation of this section of the manuscript.

\section{Setting and participants}

The study was conducted at Great Ormond Street Hospital, the regional referral centre for paediatric tumours in North London. Two senior neurosurgeons (MT and KA) performed all robot-assisted procedures.

All cases were recorded on a prospectively maintained database. The database was searched over a 2-year period between the 1st December 2015 and the 31st November 2017 to identify all children with deep-seated lesions that underwent robot-assisted stereotactic brain biopsy.

\section{Variables and data sources}

Patients had a pre-operative volumetric MRI with contrast to identify the tumour and the optimal location for biopsy was determined using a multidisciplinary approach. Images were then transferred to the Neuromate robot and an entry point (EP) and target point (TP) used to define a safe surgical trajectory that avoided eloquent tissue, vasculature, and transependymal passage. Patients were then placed under general anaesthesia, a Leksell frame placed, and a CT head performed; this was merged with the preoperative MRI scan depending on whether a transcortical or transcerebellar approach was used, patients were positioned supine or prone, respectively, and the robot docked. Once registration was performed the robot aligned the tool holder along the vector of the planned trajectory; a stereotactic biopsy using a side-cutting Sedan needle was then performed in the usual fashion.

Specimens were sent fresh for definitive histopathological analysis. A biopsy was considered positive if specimens resulted in a diagnosis based on histology or molecular markers.

A post-operative volumetric CT or MRI was performed in selected cases depending on their availability and the surgeon's preference. When accessible, the post-operative T2-weighted MRI scan and pre-operative plan were loaded on the Neuromate robot and compared by a surgeon (HJM) to assess the target point localisation error (TPLE) (Fig. 1). The TPLE is defined as the Euclidian distance between the planned and actual target (the centre of the biopsy cavity), and is calculated by determining the square root of the sum of the squares of the differences between these co-ordinates ( $x, y$, and $z$ ) (Fig. 2).

Patients were followed up approximately 2 weeks after surgery for wound review and subsequently transferred to the care of oncology unless on-going concern. Adverse events were defined as any untoward event related to a child's admission that led to an increase in hospital stay, caused neurological injury, or led to death. Adverse events within 30 days of surgery were graded and recorded prospectively in the following fashion: (1) no increase in hospital stay and no neurological injury; (2) increase in hospital stay but no neurological injury; (3) neurological injury, and (4) death. The strength of this classification system is that it records all adverse events whether or not they may be related to surgical complications.

\section{Study size and statistical methods}

The sample size was determined on a constraint-based pragmatic approach as robot-assisted stereotactic brainstem biopsies are rare. We considered a minimum of six patients sufficient for meaningful analysis.

Data were analysed using with SPSS v 20.0 (IBM, IL, USA). The mean and standard deviation were calculated for parametric variables, and the median and interquartile ranges calculated for non-parametric variables. 

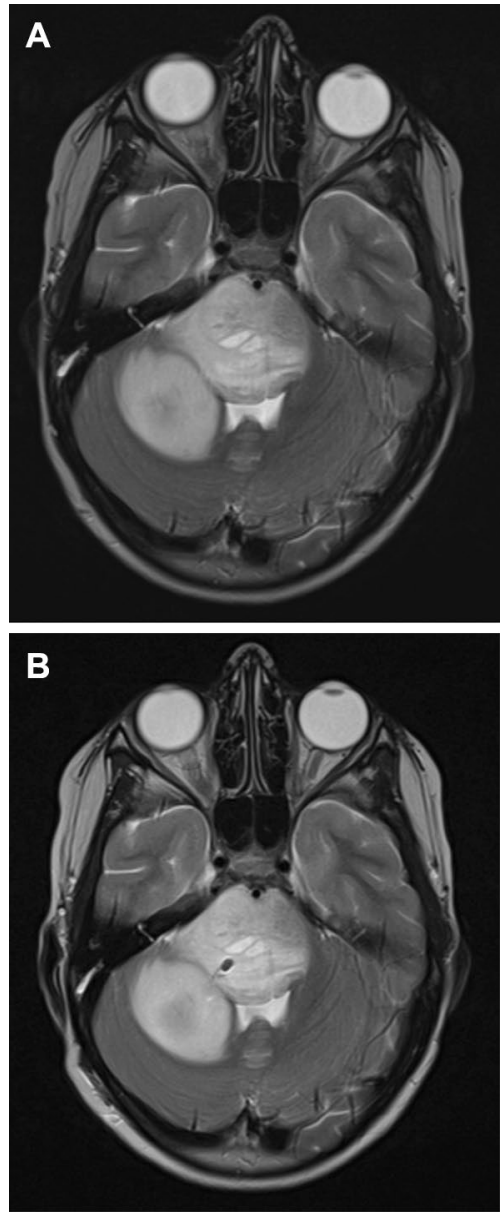

Fig. 1 a Pre-operative and b post-operative axial T2-weighted MRI scan of demonstrating pontine lesion and right-sided transcerebellar approach

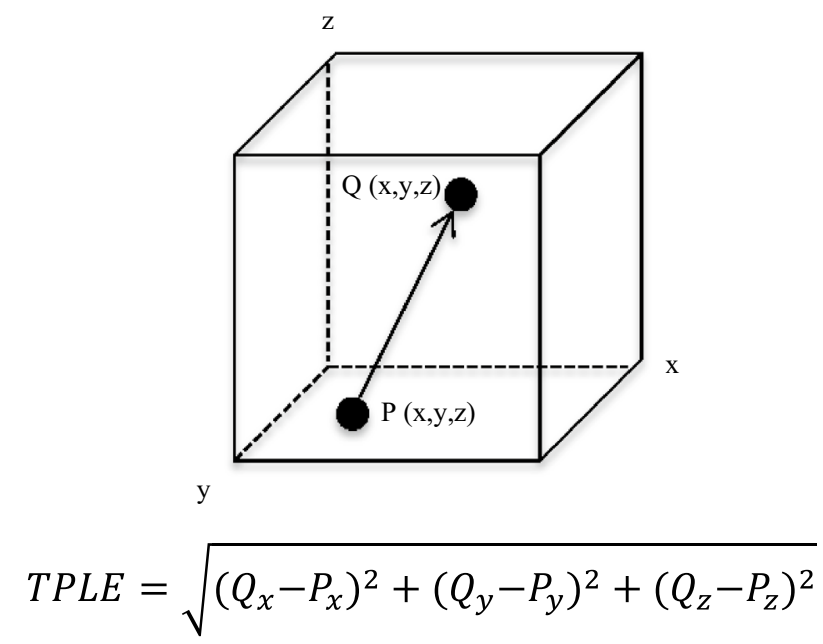

Fig. 2 Target point localisation error (TPLE) is defined as the Euclidian distance between the planned and actual target. The planned biopsy target is represented by point $P$, and the actual biopsy target by point $Q$. The arrow is the Euclidian distance between these two points

\section{Results}

\section{Participants and descriptive data}

In all, 11 consecutive children were identified with brain tumours located within the brainstem and related structures that underwent 12 robot-assisted stereotactic brain biopsies. The patient demographics are detailed in Table 1. The median age was 10 years (range $2-15$ years), and the male:female ratio was 1:1.2. Brain tumours were most commonly located in the pons (9/11) and typically a transcerebellar approach was used (9/11).

\section{Outcome data and main results}

In 10/11 cases specimens were diagnostic; in the remaining case a further biopsy was successful. The patient pathologies are detailed in Table 1. The most frequent pathology was DIPG (7/11).

Seven patients underwent an early post-operative volumetric MRI. The calculated median TPLE was $2.7 \mathrm{~mm}$ (range $0.5-4.2 \mathrm{~mm}$ ).

There were no surgical complications noted. The median length of stay was 2 days (range 2-8 days).

\section{Discussion}

\section{Principal findings}

We found that robot-assisted stereotactic brainstem biopsy in children was both feasible and safe. In our prospective cohort study, the technique was found to be accurate (median TPLE $2.7 \mathrm{~mm}$ ) and provide a high diagnostic

Table 1 Patient demographics and pathology

\begin{tabular}{lrllll}
\hline Case & Age & Sex & Location & Approach & Pathology \\
\hline 1 & 15 & M & Pons & Right transcerebellar & Inflammatory \\
2 & 12 & F & Pons & Right transcerebellar & Glioblastoma \\
3 & 11 & M & Midbrain & Right transcortical & Astrocytoma \\
4 & 2 & F & Pons & Right transcerebellar & DIPG \\
5 & 6 & F & Midbrain & Right transcortical & Astrocytoma \\
6 & 8 & M & Pons & Right transcerebellar & DIPG and \\
& & & & & radiation \\
& & & & & necrosis \\
7 & 13 & F & Pons & Left transcerebellar & DIPG \\
8 & 13 & M & Pons & Right transcerebellar & DIPG \\
9 & 5 & F & Pons & Left transcerebellar & DIPG \\
10 & 9 & F & Pons & Left transcerebellar & DIPG \\
11 & 10 & M & Pons & Right transcerebellar & DIPG \\
\hline
\end{tabular}


yield (10/11 cases). Moreover, no significant adverse events were recorded.

\section{Comparison with other studies}

The literature supporting the use of surgical robotics within neurosurgery is small but rapidly growing [14] Approximately 300 robot-assisted stereotactic brain biopsy procedures have been reported in the literature over the last 30 years, but the majority have been reported within just the last 5 years [15-22].

Several studies have reported the accuracy of robotassisted brain biopsy, albeit in adults. The average target accuracy varies in these studies from 0.9 to $4.5 \mathrm{~mm}$, and is therefore comparable to our own cohort [10, 11, 23, 24].

In the largest paediatric series to date, De Benedictis et al. used the ROSA robot (Medtech, France) and performed 128 robot-assisted surgeries on 115 consecutive children, including 26 stereotactic brain biopsy procedures [17]. Although no formal TPLE was calculated, the authors reported the technique was accurate with a tissue diagnosis in 25/26 cases. One patient had transient worsening of their neurological symptoms, but otherwise no complications were noted.

LeFranc et al. used the ROSA robot and performed robot-assisted stereotactic biopsy in 100 patients, including several children (median age 59 years; range 7-86 years) [18]. A tissue diagnosis was made in 97/100 cases. Six patients were found to have a post-operative haematoma on imaging, which were associated in transient worsening of neurological symptoms in two cases. Four further patients also had a transient worsening of their neurological symptoms.

Other studies using the ROSA robot have also found robot-assisted stereotactic biopsy in children to be feasible and safe. Miller et al. reported successful biopsy in six patients, Quick-Weller et al. in two patients, Carai et al. in seven patients, and Coca et al. in five patients [16, 19-21]; a tissue diagnosis was made in 20/20 cases, and transient worsening of neurological symptoms in only one patient.

Haegelen et al. used the Neuromate robot and performed robot-assisted stereotactic brainstem biopsy in 15 patients, including 5 children [15]. A tissue diagnosis was made in 13/15 cases. One case had permanent postoperative morbidity and two others transient morbidity.

A possible confounder when interpreting the aforementioned studies, is their use of either the transcortical or transcerebellar approach, which is frequently not reported. However, in a retrospective study Dellaretti et al. compared these approaches and found no significant difference in diagnostic yield or safety [13].

\section{Limitations}

The present study has several limitations. Unfortunately, the operative time, which has been raised as a concern with robot-assisted surgery, was not prospectively recorded. Also, early post-operative imaging was only available in selected patients limiting the assessment of accuracy.

More generally, the sample size was small as robotassisted stereotactic brainstem biopsies are rare. Lastly, the uncontrolled prospective cohort study design does not allow for rigorous comparison between robotic and standard stereotactic brain biopsy.

\section{Conclusion}

Robot-assisted stereotactic brainstem biopsy in children appears to be both feasible and safe. With rapid advances in robotics, it is likely that future platforms will become smaller, more powerful, and less costly, in a way analogous to digital computing over the last half century [25]. Eventually, a tipping point will be reached, allowing for their more widespread dissemination. To this end, research databases and comparative studies are now warranted to further assess the technique in line with the IDEAL model for safe surgical innovation.

Author contributions WD and HJM were involved in the acquisition of data, analysis of data, and drafting the manuscript. MT and KA were involved in the study conception and critical revision of the manuscript.

Funding The author(s) received no specific funding for this work.

\section{Compliance with ethical standards}

Conflict of interest All authors have completed the ICMJE uniform disclosure form at http://ww.icmje.org/coi_disclosure.pdf and declare: no financial relationships with any organisations that might have an interest in the submitted work in the previous 3 years; no other relationships or activities that could appear to have influenced the submitted work.

Ethical approval The study was registered as a Service Evaluation study with the Great Ormond Street Hospital for Children NHS Foundation Trust Clinical Audit Committee \#2237.

Informed consent Informed consent was not sought, as this was a Service Evaluation study.

Open Access This article is distributed under the terms of the Creative Commons Attribution 4.0 International License (http://creativeco mmons.org/licenses/by/4.0/), which permits unrestricted use, distribution, and reproduction in any medium, provided you give appropriate credit to the original author(s) and the source, provide a link to the Creative Commons license, and indicate if changes were made. 


\section{References}

1. Johnson KJ, Cullen J, Barnholtz-Sloan JS, Ostrom QT, Langer CE, Turner MC, McKean-Cowdin R, Fisher JL, Lupo PJ, Partap S, Schwartzbaum JA, Scheurer ME (2014) Childhood brain tumor epidemiology: a brain tumor epidemiology consortium review. Cancer Epidemiol Biomarkers Prev 23(12):2716-2736. https:// doi.org/10.1158/1055-9965.EPI-14-0207

2. Albright AL, Packer RJ, Zimmerman R, Rorke LB, Boyett J, Hammond GD (1993) Magnetic resonance scans should replace biopsies for the diagnosis of diffuse brain stem gliomas: a report from the Children's Cancer Group. Neurosurgery 33(6):1026-1029 (discussion 1029-1030)

3. Hargrave D, Bartels U, Bouffet E (2006) Diffuse brainstem glioma in children: critical review of clinical trials. Lancet Oncol 7(3):241-248. https://doi.org/10.1016/S1470-2045(06)70615-5

4. Mackay A, Burford A, Carvalho D, Izquierdo E, Fazal-Salom J, Taylor KR, Bjerke L, Clarke M, Vinci M, Nandhabalan M, Temelso S, Popov S, Molinari V, Raman P, Waanders AJ, Han HJ, Gupta S, Marshall L, Zacharoulis S, Vaidya S, Mandeville HC, Bridges LR, Martin AJ, Al-Sarraj S, Chandler C, Ng HK, Li X, Mu K, Trabelsi S, Brahim DH, Kisljakov AN, Konovalov DM, Moore AS, Carcaboso AM, Sunol M, de Torres C, Cruz O, Mora J, Shats LI, Stavale JN, Bidinotto LT, Reis RM, Entz-Werle N, Farrell M, Cryan J, Crimmins D, Caird J, Pears J, Monje M, Debily MA, Castel D, Grill J, Hawkins C, Nikbakht H, Jabado N, Baker SJ, Pfister SM, Jones DTW, Fouladi M, von Bueren AO, Baudis M, Resnick A, Jones C (2017) Integrated molecular meta-analysis of 1,000 pediatric high-grade and diffuse intrinsic pontine glioma. Cancer Cell 32(4):520-537 e525. https://doi. org/10.1016/j.ccell.2017.08.017

5. Puget S, Beccaria K, Blauwblomme T, Roujeau T, James S, Grill J, Zerah M, Varlet P, Sainte-Rose C (2015) Biopsy in a series of 130 pediatric diffuse intrinsic Pontine gliomas. Childs Nerv Syst 31(10):1773-1780. https://doi.org/10.1007/s00381-015-2832-1

6. Hamisch C, Kickingereder P, Fischer M, Simon T, Ruge MI (2017) Update on the diagnostic value and safety of stereotactic biopsy for pediatric brainstem tumors: a systematic review and meta-analysis of 735 cases. J Neurosurg Pediatr 20(3):261-268. https://doi.org/10.3171/2017.2.PEDS1665

7. Perez-Gomez JL, Rodriguez-Alvarez CA, Marhx-Bracho A, Rueda-Franco F (2010) Stereotactic biopsy for brainstem tumors in pediatric patients. Childs Nerv Syst 26(1):29-34. https://doi. org/10.1007/s00381-009-1000-x

8. Drake JM, Joy M, Goldenberg A, Kreindler D (1991) Computerand robot-assisted resection of thalamic astrocytomas in children. Neurosurgery 29(1):27-33

9. Bekelis K, Radwan TA, Desai A, Roberts DW (2012) Frameless robotically targeted stereotactic brain biopsy: feasibility, diagnostic yield, and safety. J Neurosurg 116(5):1002-1006. https://doi. org/10.3171/2012.1.JNS111746

10. Willems PW, Noordmans HJ, Ramos LM, Taphoorn MJ, Berkelbach van der Sprenkel JW, Viergever MA, Tulleken CA (2003) Clinical evaluation of stereotactic brain biopsies with an MKMmounted instrument holder. Acta Neurochir 145(10):889-897. https://doi.org/10.1007/s00701-003-0112-4 (discussion 897)

11. Glauser D, Fankhauser H, Epitaux M, Hefti JL, Jaccottet A (1995) Neurosurgical robot Minerva: first results and current developments. J Image Guided Surg 1(5):266-272. https ://doi.org/10.1002/(SICI)1522-712X(1995)1:5\%3C266 ::AID-IGS2\%3E3.0.CO;2-8

12. Kwoh YS, Hou J, Jonckheere EA, Hayati S (1988) A robot with improved absolute positioning accuracy for CT guided stereotactic brain surgery. IEEE Trans Bio-med Eng 35(2):153-160. https:// doi.org/10.1109/10.1354

13. Dellaretti M, Reyns N, Touzet G, Dubois F, Gusmao S, Pereira JL, Blond S (2012) Stereotactic biopsy for brainstem tumors: comparison of transcerebellar with transfrontal approach. Stereotact Funct Neurosurg 90(2):79-83. https://doi.org/10.1159/000335502

14. Marcus HJ, Seneci CA, Payne CJ, Nandi D, Darzi A, Yang GZ (2014) Robotics in keyhole transcranial endoscope-assisted microsurgery: a critical review of existing systems and proposed specifications for new robotic platforms. Neurosurgery 10(Suppl 1):84-95. https://doi.org/10.1227/NEU.0000000000000123

15. Haegelen C, Touzet G, Reyns N, Maurage CA, Ayachi M, Blond S (2010) Stereotactic robot-guided biopsies of brain stem lesions: experience with 15 cases. Neurochirurgie 56(5):363-367. https:// doi.org/10.1016/j.neuchi.2010.05.006

16. Carai A, Mastronuzzi A, De Benedictis A, Messina R, Cacchione A, Miele E, Randi F, Esposito G, Trezza A, Colafati GS, Savioli A, Locatelli F, Marras CE (2017) Robot-assisted stereotactic biopsy of diffuse intrinsic pontine glioma: a single-center experience. World Neurosurg 101:584-588. https://doi.org/10.1016/j. wneu.2017.02.088

17. De Benedictis A, Trezza A, Carai A, Genovese E, Procaccini E, Messina R, Randi F, Cossu S, Esposito G, Palma P, Amante P, Rizzi M, Marras CE (2017) Robot-assisted procedures in pediatric neurosurgery. Neurosurg Focus 42(5):E7. https://doi. org/10.3171/2017.2.FOCUS16579

18. Lefranc M, Capel C, Pruvot-Occean AS, Fichten A, Desenclos C, Toussaint P, Le Gars D, Peltier J (2015) Frameless robotic stereotactic biopsies: a consecutive series of 100 cases. J Neurosurg 122(2):342-352. https://doi.org/10.3171/2014.9.JNS14107

19. Miller BA, Salehi A, Limbrick DD Jr, Smyth MD (2017) Applications of a robotic stereotactic arm for pediatric epilepsy and neurooncology surgery. J Neurosurg Pediatr 20(4):364-370. https ://doi.org/10.3171/2017.5.PEDS1782

20. Quick-Weller J, Tritt S, Behmanesh B, Mittelbronn M, Spyrantis A, Dinc N, Weise L, Seifert V, Marquardt G, Freiman TM (2017) Biopsies of pediatric brainstem lesions display low morbidity but strong impact on further treatment decisions. J Clin Neurosci 44:254-259. https://doi.org/10.1016/j.jocn.2017.06.028

21. Coca HA, Cebula H, Benmekhbi M, Chenard MP, Entz-Werle N, Proust F (2016) Diffuse intrinsic pontine gliomas in children: interest of robotic frameless assisted biopsy. A technical note. Neurochirurgie 62(6):327-331. https://doi.org/10.1016/j.neuch i.2016.07.005

22. Marcus HJ, Vakharia VN, Ourselin S, Duncan J, Tisdall M, Aquilina K (2018) Robot-assisted stereotactic brain biopsy: systematic review and bibliometric analysis. Childs Nerv Syst. https://doi. org/10.1007/s00381-018-3821-y

23. Minchev G, Kronreif G, Martinez-Moreno M, Dorfer C, Micko A, Mert A, Kiesel B, Widhalm G, Knosp E, Wolfsberger S (2017) A novel miniature robotic guidance device for stereotactic neurosurgical interventions: preliminary experience with the iSYS1 robot. J Neurosurg 126(3):985-996. https://doi.org/10.3171/2016.1.JNS15 2005

24. Dlaka D, Svaco M, Chudy D, Jerbic B, Sekoranja B, Suligoj F, Vidakovic J, Almahariq F, Romic D (2018) Brain biopsy performed with the RONNA G3 system: a case study on using a novel robotic navigation device for stereotactic neurosurgery. Int J Med Robot 14(1):e1884. https://doi.org/10.1002/rcs.1884

25. Marcus H, Nandi D, Darzi A, Yang GZ (2013) Surgical robotics through a keyhole: from today's translational barriers to tomorrow's “disappearing” robots. IEEE Trans Bio-med Eng 60(3):674-681. https://doi.org/10.1109/TBME.2013.2243731 